\title{
Ocular penetrating injuries in children
}

\author{
Imane Chabbar $\odot$, Amina Berraho $\odot$ \\ Ophthalmology B Department, Ibn Sina University Hospital, Rabat, Morocco
}

\begin{abstract}
BACKGROUND: Ocular penetrating injuries in children are common and potentially serious. They take on a special character because of the major risk of amblyopia that they generate in children. The objective of this work is to analyze the epidemiological and clinical aspects of these serious traumas and to study the functional prognosis in Moroccan children.

MATERIAL AND METHODS: We conducted a retrospective study of 83 children between January 2016 and December 2019. The average age of children is 6.5 years, with 64 boys and 19 girls.

RESULTS: The circumstances of penetrating eye injuries are accidental dominated by street games. Corneal wounds represented $67.5 \%$ associated with iris prolapse in 39 cases and hyphema in 34 cases. In $30.1 \%$ of cases, a posttraumatic cataract is associated, and a foreign body is detected in $6 \%$ of cases. Final visual acuity $\geq 5 / 10$ is objectified in $30 \%$ of cases.

CONCLUSIONS: This study highlights the importance of preventing these serious childhood traumas by implementing education and awareness-raising measures.
\end{abstract}

KEY WORDS: penetrating eye injury; children; management; prognosis

Ophthalmol J 2020; Vol. 5, 120-124

\section{INTRODUCTION}

Penetrating eye injuries represent a major threat to vision, whether at work, at home, during sport [1] but also at school. They are responsible not only for unilateral blindness [2,3] but also for a profound emotional trauma for patients and their families [2]. Treatment is long and expensive, but despite this, the prognosis is often severe. These perforating traumas take on a special character in children because of the major risk of amblyopia that they generate. Their socio-economic repercussions are very important because they involve the educational and professional future of these child victims. The causes of these traumas are multiple and are directly linked to the socio-economic level of each country [4]. Several studies conducted in developed [5, 6] and underdeveloped countries [7-9] have analyzed the epidemiological parameters and risk factors associated with the occurrence of penetrating ocular injuries.
The objective of this study is to determine the epidemiological and clinical characteristics of penetrating eye injuries in Moroccan children, the main causes adapted to the Moroccan socio-economic context and the impact on the visual prognosis of these child victims.

\section{MATERIAL AND METHODS}

We conducted a retrospective study of children aged from 0 to 14 years presenting penetrating eye injuries, hospitalized in Ophthalmology B Department at Ibn-Sina University Hospital in Rabat-Morocco. The period covered was between January 2016 and December 2019.

Penetrating eye injury in this study was defined as an open globe injury with or without a retained intraocular foreign body. 
Three age groups were studied: pre-schoolers $0-5$ years, school-aged $6-10$ years, and adolescents 12-14 years.

We collected for each case demographic parameters (age, sex, origin), the admission delay, the circumstances, place and agent of the trauma. The slit-lamp examination specified the anatomical location of the lesions, uveal prolapse and ocular structures damage in order to assess the severity of the trauma. We noted the surgical treatment and the final visual outcome of each patient.

\section{RESULTS \\ AGE, SEX}

A total of 83 children presenting penetrating eye injuries were identified with male predominance (64 boys and 19 girls).

The average age of children was 6.5 years with extremes between 18 months and 14 years. 74.7\% of children came from urban areas (62 cases). Penetrating eye injuries were more common in the 6-14 age group (Fig. 1).

\section{DELAY OF THE ADMISSION}

Thirty four cases (38.5 \%) were taken to hospital the same day, 29 cases $(35 \%)$ were taken the day after the trauma. Sixteen cases (19.3\%) were taken between $48 \mathrm{~h}$ and one week after the trauma. The maximum consultation delay was 10 days in 4 children from rural areas.

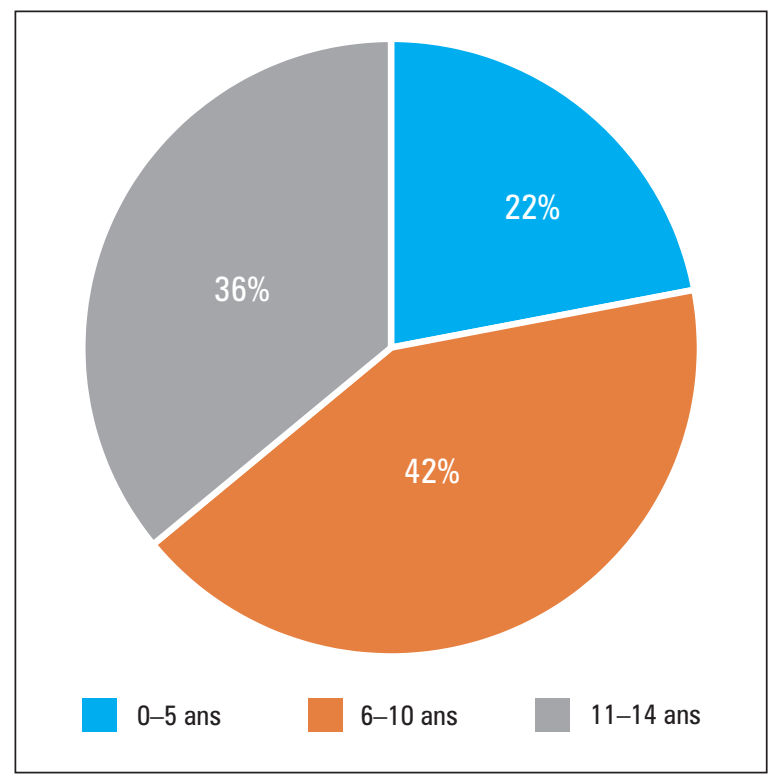

FIGURE 1. Distribution of penetrating eye injuries by age group

\section{CIRCUMSTANCES OF THE TRAUMA}

Circumstances of the trauma are presented in Figure 2. The street was the predominant place of these ocular trauma accidentally occurring during children's games. The second place was domestic accidents at home. Two cases of eye injuries have occurred in school. One case of a 14-year-old child, injured at the workplace, has been noted: He was a blacksmith, injured by a foreign object when he hammered a metal bar.

\section{AGENT OF THE TRAUMA}

The nature of the traumatic agent was identified in the majority of cases (Fig. 3).

The agent of trauma was metallic in $37 \%$ of cases (wire, knife), then tree branches especially in rural areas, stone throws was the third cause during children brawls.

\section{ANATOMICAL LOCATION}

Penetrating eye injuries were unilateral in all cases, involving the right eye in 38 cases and the left eye in 45 cases (Fig. 4, 5).

Corneal wounds represented $67.5 \%$ of cases, scleral wounds $7.2 \%$ and corneoscleral wounds $25.3 \%$ of cases.

\section{SLIT LAMP EXAMINATION}

The slit lamp examination objectified an iris prolapse in 39 cases, a hyphema in 34 cases, a posttraumatic cataract in 25 cases and an involvement of the

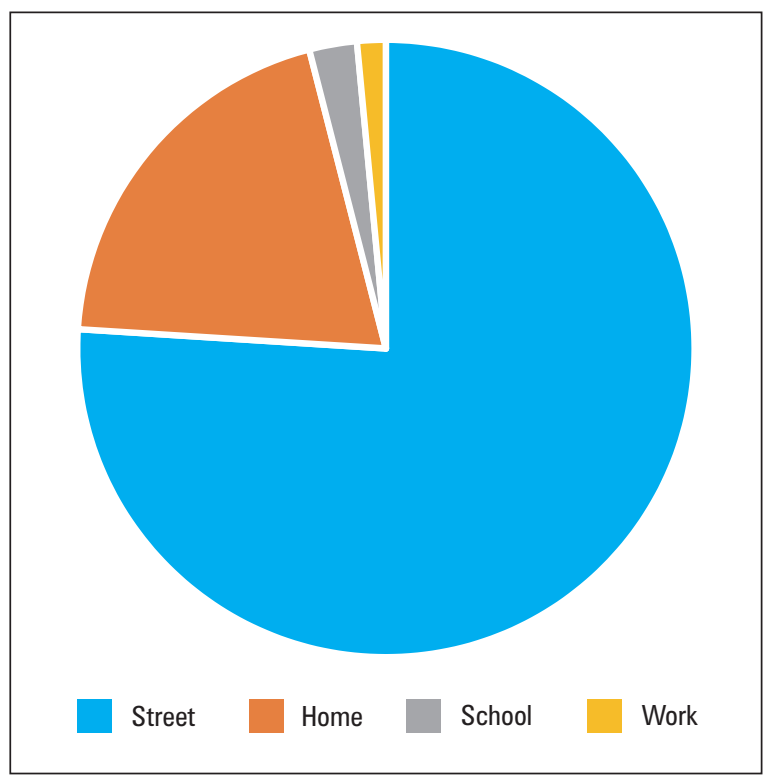

FIGURE 2. Circumstances of trauma 


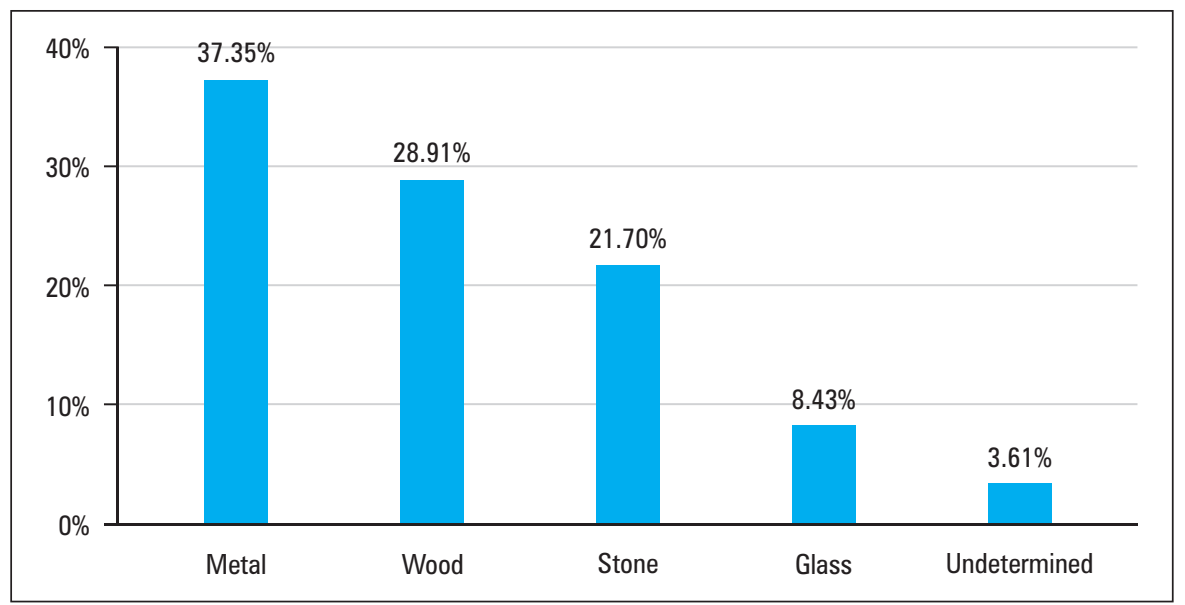

FIGURE 3. Agent of trauma

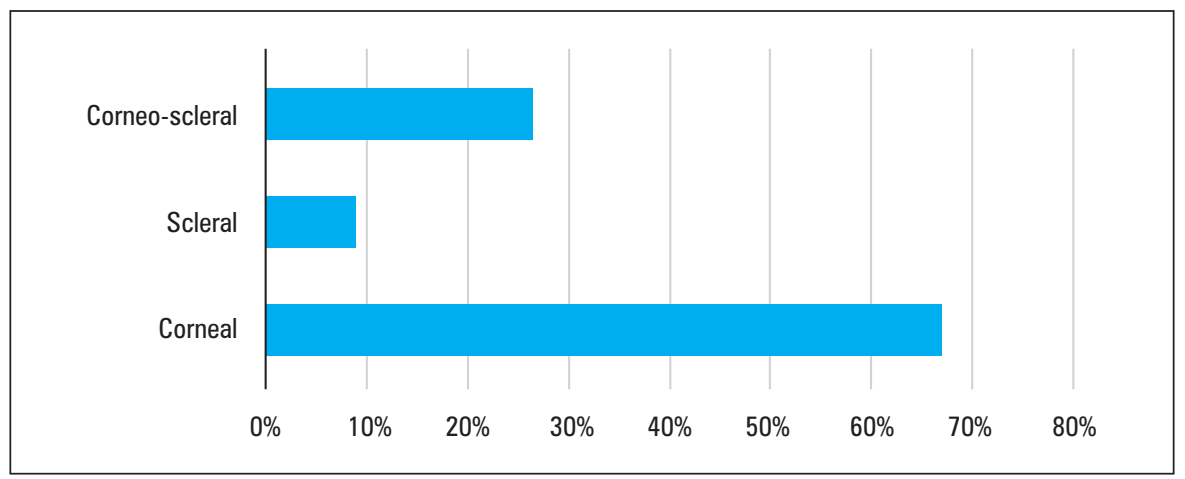

FIGURE 4. Anatomical location of ocular penetrating injuries

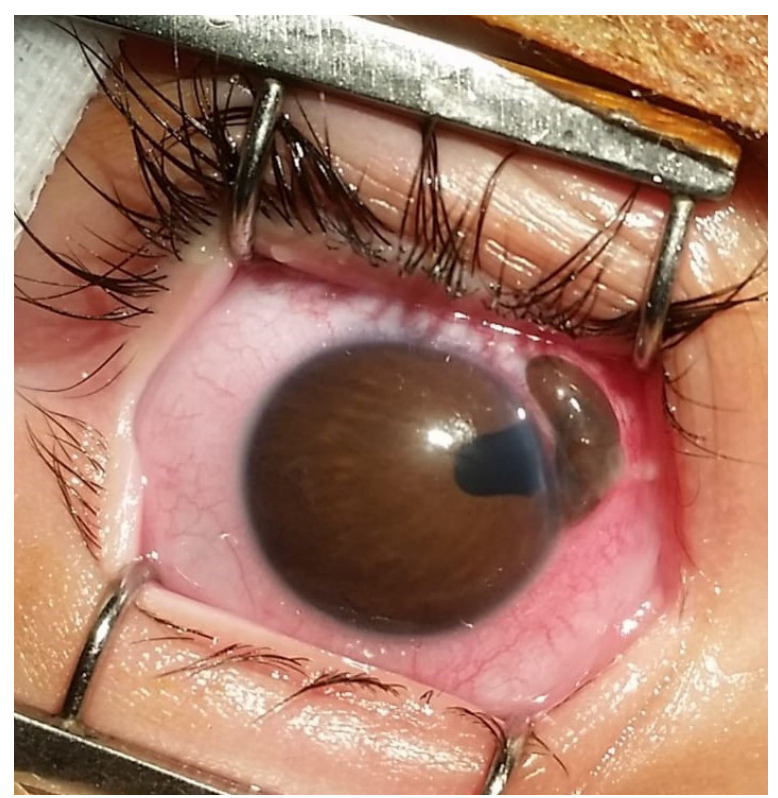

FIGURE 5. Paralimbic scleral wound with iris prolapse and flat anterior chamber in an 18-month-old infant posterior segment in 13 cases. In $6 \%$ of cases, a retained foreign body was detected clinically or radiologically: of corneal location in two cases, in the anterior chamber in two cases and in the vitreous in one case.

\section{SURGICAL MANAGEMENT}

Surgical management under general anesthesia was performed in all cases. It consisted of a surgical exploration with eye damage assessment followed by suturing of wounds after possible reintegration of the prolapsed uvea (Fig. 6). No evisceration was carried out.

\section{OVERALL VISUAL OUTCOME}

The initial visual acuity before surgical treatment was noted in cooperating children. It varied between $5 / 10$ and $7 / 10$ in 13 patients $(15,6 \%)$, between $5 / 10$ and $3 / 10$ in 21 children $(25,3 \%), \leq 1 / 10$ in 26 children $(31.3 \%)$ and was not measurable in 23 children $(27.7 \%)$. 

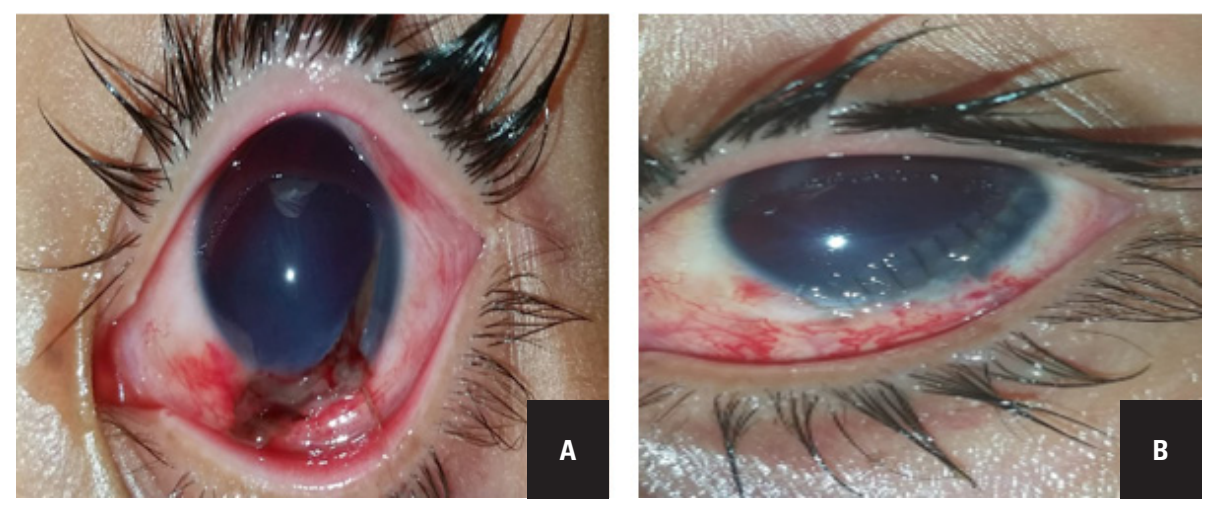

FIGURE 6. A. Corneal wound extended from 3 to 8 o'clock with total hyphema. B. Postoperative appearance after anterior chamber washout and corneal suturing

After surgical management and during the follow-up, a final visual acuity $\geq 5 / 10$ was objectified in 25 cases $(30 \%)$ of which $15(18 \%)$ returned to normal vision. While 5 cases $(6 \%)$ had a negative light perception progressing towards the phthisis bulbi. The poor visual outcome was especially objectified in children presenting severe penetrating injuries with involvement of the posterior segment.

\section{DISCUSSION}

Ocular penetrating injuries are a major and preventable cause of childhood blindness. The World Health Organization (WHO) records some 55 million eye injuries per year, responsible for 19 million cases of monocular blindness, 32 to $75 \%$ of which occur in children $[2,4]$. The male predominance in our study agrees with the literature $[10,11]$. This high incidence of eye injuries in the 6-10 and 11-14 age groups is explained by the fact that school-aged children spend more time away from home and parental authority. Most of our patients were of urban origin. This is explained, on the one hand, by the scarcity and the remoteness of medical centers in rural areas and on the other hand by the lack of financial means; from where the interest of the creation of primary health centers for first aid and referral of patients to specialized centers. Most of our patients consulted 24 to 48 hours after the trauma. The long consultation delay of our 4 children was due either to an underestimation of the initial lesion or to the lack of financial means for the trip from the landlocked rural area. The place of predilection for these accidents was the street where children are engaged in games away from adult supervision. These find- ings do not join those of other studies [12] where the home is the main place of these accidents. This difference is probably due to cultural or climatic factors specific to each country. Despite the clear legislation prohibiting the work of minor children, we have identified one case of eye injury occurring at the workplace, which must encourage public authorities to rigorously apply and monitor the laws in force. Metallic agents (knives, scissors and metallic wires), vegetable thorns and stone-throwing represent the main traumatic agents. The severity of ocular lesions is directly linked to the sharp nature of traumatic agents, to which is added the septic risk linked to the plant or telluric nature of traumatic agents. Post-traumatic cataract has been associated in $30.1 \%$ of cases, it essentially poses the problem of aphakia correction [13] particularly in children who could not be implanted because of traumatic capsular rupture or zonular disinsertion [14]. The associated damage of posterior segment conditions the visual prognosis [15] since it can cause functional loss of the eye despite early and adequate treatment.

Visual outcome was poor in our series, however, it is difficult to compare our results with other studies because of the inconsistency of the parameters studied [4]. The prevention of these serious accidents remains a public health problem. It is based on the health and social education of the population, the creation of play areas suitable for children far from the violence of streets and the improvement of access to health care services [16].

\section{CONCLUSION}

Ocular penetrating injuries in children remain poor prognosis. Street games accidents away from 
adult's supervision are the most frequent causes. The school-aged boys are the most exposed. The violence of the trauma and the functional results threaten the eyes of these children. Only prevention with an action strategy adapted to each society allows the fight against this major and preventable cause of blindness.

\section{Conflict of interest}

The authors do not declare any conflict of interest.

\section{REFERENCES}

1. McCormack P. Penetrating injury of the eye. Br J Ophthalmol. 1999; 83(10): 1101-1102, doi: 10.1136/bjo.83.10.1101, indexed in Pubmed: 10502565.

2. Négrel $A D$, Thylefors $B$. The global impact of eye injuries. Ophthalmic Epidemiol. 1998; 5(3): 143-169, doi: 10.1076/opep.5.3.143.8364, indexed in Pubmed: 9805347.

3. Thylefors B. Epidemiological patterns of ocular trauma. Aust N Z J Ophthalmol. 1992; 20(2): 95-98, doi: 10.1111/j.1442-9071.1992. tb00718.x, indexed in Pubmed: 1389141.

4. Rostomian K, Thach A, Isfahani A, et al. Open globe injuries in children. J AAPOS. 1998; 2(4): 234-238, doi: 10.1016/s1091-8531(98)90058-1, indexed in Pubmed: 10532742

5. Fong LP. Eye injuries in Victoria, Australia. Med J Aust. 1995; 162(2): 64-68, indexed in Pubmed: 7838028.

6. Blomdahl S, Norell S. Perforating eye injury in the Stockholm population. An epidemiological study. Acta Ophthalmol (Copenh). 1984; 62(3): 378-390, doi: 10.1111/j.1755-3768.1984.tb08418.x, indexed in Pubmed: 6464687.
7. Gothwal VK, Adolph S, Jalali S, et al. Demography and prognostic factors of ocular injuries in South India. Aust N Z J Ophthalmol. 1999; 27(5): 318-325, doi: 10.1046/j.1440-1606.1999.00225.x, indexed in Pubmed: 10571392.

8. Umeh RE, Umeh OC. Causes and visual outcome of childhood eye injuries in Nigeria. Eye (Lond). 1997; 11 (Pt 4): 489-495, doi: 10.1038/ eye.1997.132, indexed in Pubmed: 9425413.

9. Oluyemi F. Epidemiology of penetrating eye injury in ibadan: a 10-year hospital-based review. Middle East Afr J Ophthalmol. 2011; 18(2): 159-163, doi: 10.4103/0974-9233.80706, indexed in Pubmed: 21731328.

10. Farr AK, Hairston RJ, Humayun MU, et al. Open globe injuries in children: a retrospective analysis. J Pediatr Ophthalmol Strabismus. 2001; 38(2): 72-77, indexed in Pubmed: 11310710.

11. Beby F, Kodjikian L, Roche 0 , et al. Traumatismes oculaires perforants de l'enfant. J Fran Ophtalmol. 2006; 29(1): 20-23, doi: 10.1016/ s0181-5512(06)73742-1.

12. Thompson CG, Kumar N, Billson FA, et al. The aetiology of perforating ocular injuries in children. Br J Ophthalmol. 2002; 86(8): 920-922, doi: 10.1136/bjo.86.8.920, indexed in Pubmed: 12140216.

13. Khokhar S, Gupta S, Yogi R, et al. Epidemiology and intermediate-term outcomes of open- and closed-globe injuries in traumatic childhood cataract. Eur J Ophthalmol. 2014; 24(1): 124-130, doi: 10.5301/ ejo.5000342, indexed in Pubmed: 23918072.

14. Krishnamachary M, Rathi V, Gupta S. Management of traumatic cataract in children. J Cataract Refract Surg. 1997; 23 Suppl 1: 681-687, doi: 10.1016/s0886-3350(97)80054-5, indexed in Pubmed: 9278825.

15. Knyazer B, Levy J, Rosen $S$, et al. Prognostic factors in posterior open globe injuries (zone-III injuries). Clin Exp Ophthalmol. 2008; 36(9): 836-841, doi: 10.1111/j.1442-9071.2009.01922.x, indexed in Pubmed: 19278478.

16. World Health Organization. Preventing blindness in children. Report of a WHO/IAPB scientific meeting. Hyderabad, India 1999. 